\title{
On the Formation of Internal Cracks in Continuously Cast Slabs*
}

\section{By Hiromu FUJII,** Tetsuro OHASHI** and Takeshi HIROMOTO***}

\section{Synopsis}

In order to make clear the mechanism for the formation of internal cracks in slabs continuously cast by a bow type machine, effects of casting conditions on the formation of the cracks were sorted out. At the same time, the metallographic structure of the area adjacent to the internal cracks was studied. Also, the situation under which generation and growth of the internal cracks took place was estimated by means of radioisotope. The followings are findings:

(1) Under the casting conditions selected for the present study, major cause of the internal crack generation is the stress arising from bulging correction. Excessive casting speed and insufficient specific cooling water are two large factors contributing to the formation of the internal cracks. Effects of solute elements are also observed.

(2) The internal crack is a crack generated in the vicinity of the solidliquid interface, in which solute enriched liquid existing at the solid-liquid interface is filled. It is confirmed that such a crack gradually grows during repeated bulging and straightening of solidifying shell as the slab travel through the roller apron of the machine.

\section{Introduction}

As compared with the conventional ingot casting and rolling method, continuous casting excells in yield and energy- and labor-saving. This process has become very popular in the 1970's. The continuous casting method, with such advantages, is not free from disadvantages. For one thing, it is low in productivity. While high casting speed is used as a means of compensating for this low productivity, generation of internal cracks at high casting speed is a detrimental factor.

For blooms and billets, whose continuous casting began earlier than that of slabs, numerous reports on the study of internal cracks have been presented since about $1960 .{ }^{1-5)} \quad$ These studies cite the following four points as operational factors contributive to internal cracks: (1) excessive secondary cooling, (2) recalescence of slab surface, (3) excessive pinch roll pres- sure, and (4) high casting temperature. Adams ${ }^{6)}$ and Lankford ${ }^{7)}$ investigated embrittlement of the cast slab at high temperature in their study into the machanism of internal crack generation.

In order to get a qualitative picture of the mechanism causing internal cracks in slabs continuously cast by a bow type machine, the effects of casting conditions were sorted out. At the same time, the metallographic structure of areas adjacent to internal cracks was investigated to study the mechanism of generation and growth of such cracks.

\section{Experimental Method}

Sulfur print was made of various kinds of slabs cast by a bow type machine with $10.5 \mathrm{~m}$ radius at Hirohata Works, and form, distribution and other characteristics of the internal cracks were examined. Table 1 outlines main casting conditions and types of steels.

The dendritic- and metallographic-structure in the vicinity of the internal crack were studied. Also, electron probe microanalysis and scanning electron microscopic examination were made. Furthermore, to observe generation and growth of the internal crack, radioisotope was added during casting.

\section{Status of Generation of Internal Cracks}

\section{Effects of Slabmaking Conditions}

As is commonly known, the form of internal cracks in the continuously cast slab is such that cracks, each occupying some area, lie parallel to the slab width direction at almost a regular pitch in the casting direction. Generation of such cracks is closely related to casting conditions. Except for the case of abnormality

Table 1. Casting conditions and chemical compositions of test slabs

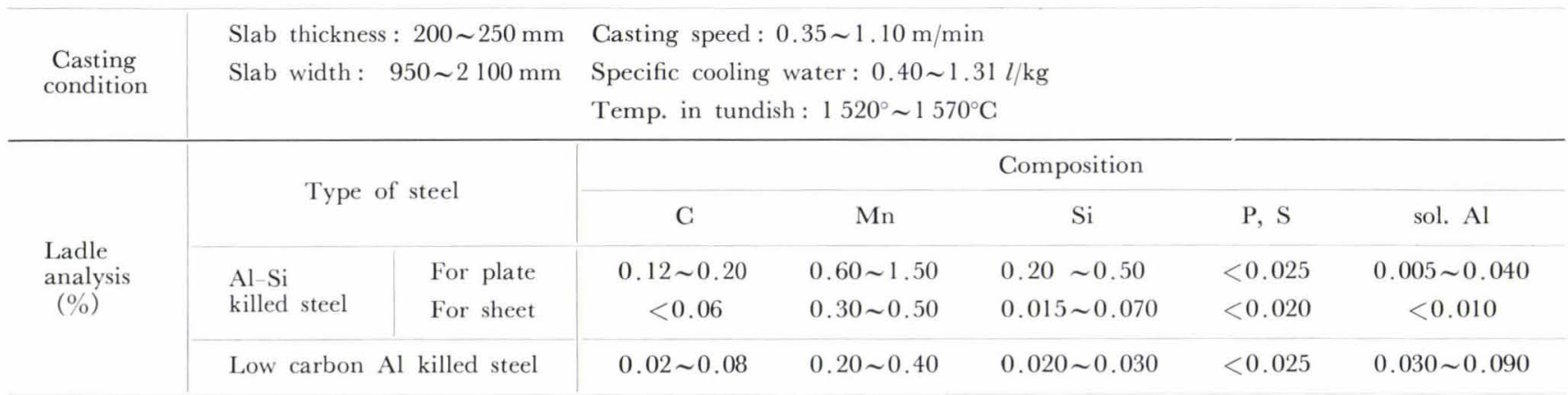

* Originally published in Tetsu-to-Hagané, 62 (1976), 1813, in Japanese. English version received June 23 , 1977.

** Technical Research Office, Hirohata Works, Nippon Steel Corp., Hirohata-ku, Himeji 671-11.

*** Kyushu Works, Nittetsu Kinzoku Kogyo, Ltd., Buzen-shi, Fukuoka 828. 
in roll alignment, as far as the same type of steels and same size of slabs are concerned, the casting speed and specific cooling water are the major determinants for the generation of the cracks. One such example is Fig. 1, which gives the result on Al-Si killed steel slabs, $250 \mathrm{~mm}$ thick and $1900 \sim 2000 \mathrm{~mm}$ wide, for plates. According to this study, the larger the casting speed and the smaller the specific cooling water are, the easier it becomes for internal cracks to occur.

The casting temperature also influences the generation of internal cracks. It is found that the lower the casting temperature is, the more difficult it becomes for internal cracks to occur.

For even closer examination of the mechanism of generation of internal cracks, Fig. 2 shows the length and pitch of internal cracks observed on the longitudinal section of the $\mathrm{Al}-\mathrm{Si}$ killed steel slabs as a function of casting speed. An average of the distance from a crack of a certain length to its neighboring

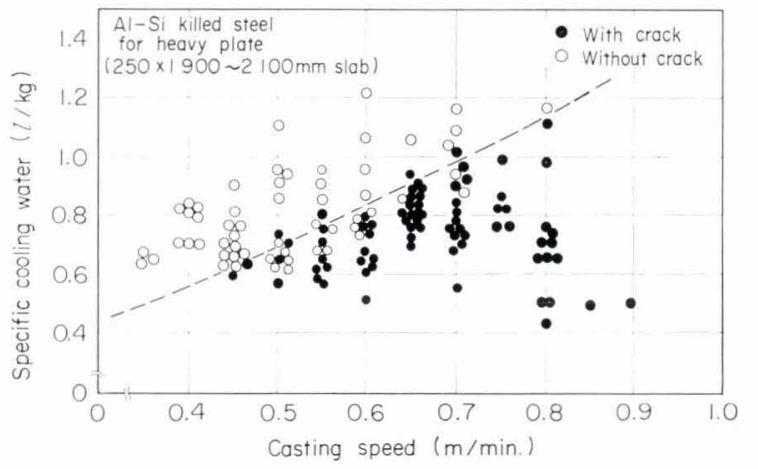

Fig. 1. Effects of casting speed and specific cooling water on the formation of internal cracks

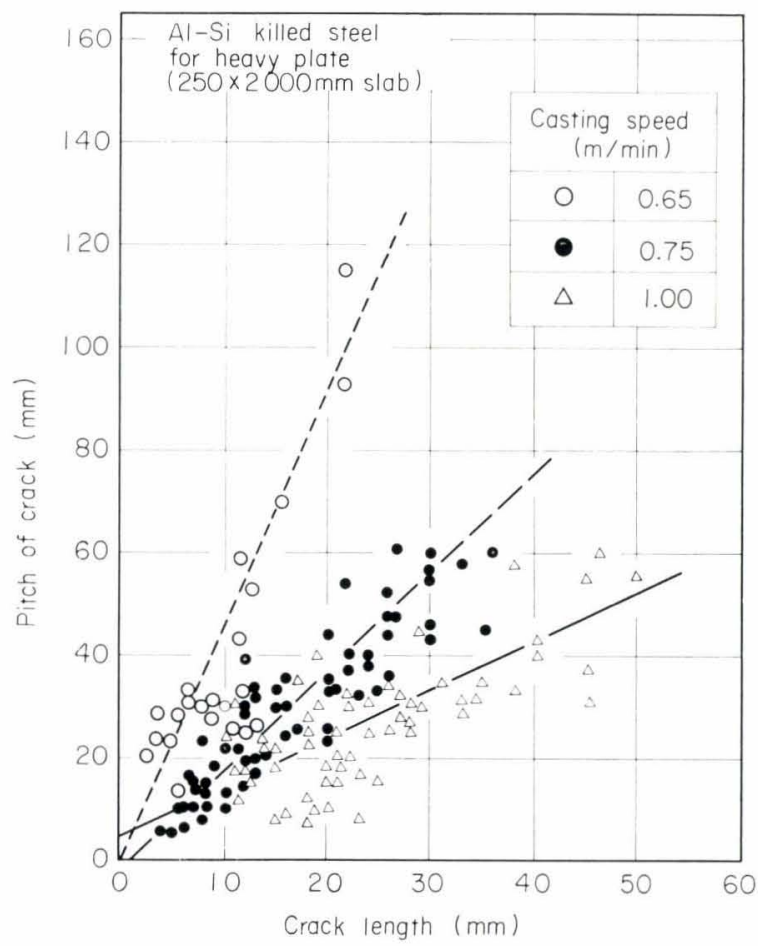

Fig. 2. Relation between casting speed and crack distribution observed on longitudinal cross section cracks is taken as the pitch corresponding to the length of the internal crack. Figure 2 indicates that regardless of the casting speed, the crack length increases with increasing crack pitch, although the larger the casting speed is, the longer the crack becomes and the smaller the pitch becomes. As explained later, judging from a gradual development of internal cracks, the fact that the crack length becomes longer as the casting speed is made faster, is based on broadening the range in which cracks are generated and permitted to grow. When we assume that cracks are caused to relieve strain in the inner surface of the shell and that critical strain inducing cracks is constant, it seems that the pitch is getting smaller as the casting speed increases, as a result of an increase in the rate of accumulating strain inside the shell.

\section{Effects of Molten Steel Components}

Figure 3 shows the frequency of the formation of internal cracks at different carbon contents in three types of steel: Al-Si killed steel for plates with 0.12 to $0.20 \% \mathrm{C}$, Al killed steel for cold-rolled sheets with 0.02 to $0.08 \% \mathrm{C}$ and $\mathrm{Al}-\mathrm{Si}$ killed steel for cold-rolled sheets with less than $0.06 \% \mathrm{C}$. It demonstrates that the internal crack tends to occur as the $\mathrm{C}$ content increases. The $\mathrm{Mn}$ and $\mathrm{Si}$ contents of the three types of steel vary somewhat as indicated in Table 1 . It is confirmed, however, that when the contents of the two elements are changed in one type of steel, very little effects are caused on the formation of internal cracks. It is considered that the difference in the frequency of the formation as shown in Fig. 3 is due to the difference in $\mathrm{C}$ content.

Also, in order to find out the effects of S content, the frequency of the formation of internal cracks in Al-Si killed steel slabs for plates when only the $\mathrm{S}$ content is altered, is shown in Fig. 3. A decrease in $\mathrm{S}$ content results in a reduction of the frequency of crack formation.

\section{Effects of the Solidification Structure}

For the Al-Si killed steel cast by the bow type machine, the equiaxed dendritic structure is formed in the area from about the center towards the lower side of thickness. ${ }^{8)}$ In the type of steel, which con-

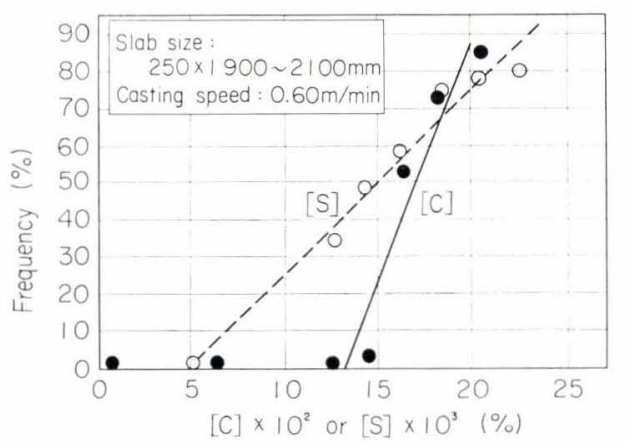

Fig. 3. Effects of $\mathrm{C}$ or $\mathrm{S}$ content on the frequency of internal cracks. The frequency is the ratio of the number of heats with internal cracks to the total number of heats. 
tains a different dendritic structure for the loose (upper) and fixed (lower) sides of the slab, not only the form of internal cracks varies with the difference in the dendritic structure but also there is a difference in ease with which such cracks are generated, as shown in Photo. 1 (a). There are much more internal cracks in the loose side than in the fixed side. On the other hand, in the case of the low $\mathrm{C}-\mathrm{Al}$ killed steel, whose loose and fixed sides are of the same columnar dendritic structure, there is the same degree of frequency of internal crack formation as shown in Photo. 1 (b).
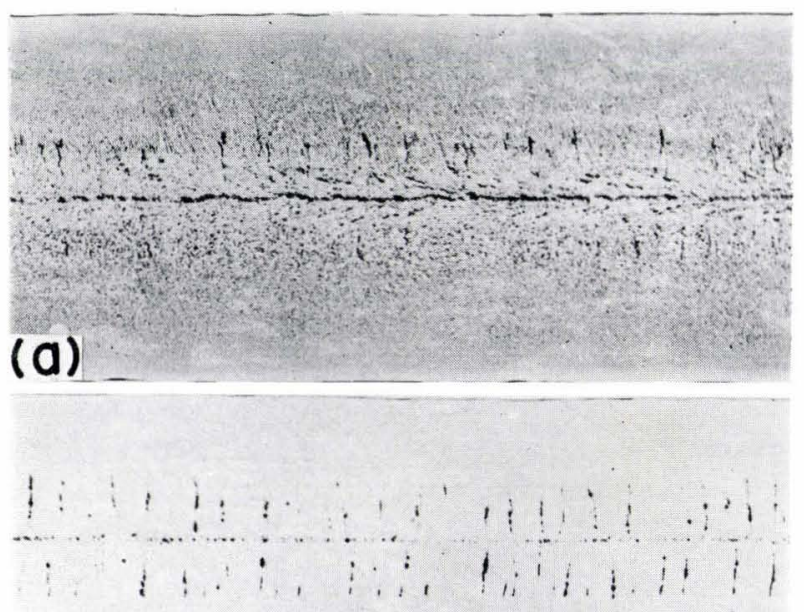

(b)

\section{$10 \mathrm{~cm}$}

(a) $\mathrm{Al}-\mathrm{Si}$ killed steel with equiaxed crystals

(b) Low C-Al killed steel without equiaxed crystals

Photo. 1. Effect of the solidification structure on the formation of internal cracks (observed in sulfur print)
From the above results, it is estimated that existence of the equiaxed dendrite makes it difficult for internal cracks to occur. If we consider the results of measuring the shell thickness, under the casting conditions for Al-Si killed steel slabs for plates as shown in Photo 1, full solidification has been reached before the unbending point. Hence, it is considered that stress due to bulging correction and thermal stress constitute the main stress inside the shell, which is responsible for causing internal cracks. In this sense, there is no difference in the stress inside the shell between the loose and fixed sides. For the cause of the tendency of internal cracks to occur in the loose side, the difference in the dendritic structure can be pointed out as explained above.

\section{Metallographic Examination of Internal Cracks}

\section{Relationships with the Dendritic Structure}

An example of the dendritic structure of the $\mathrm{Al}$ Si killed steel slab is provided in Photo. 2. Not only in the $\mathrm{Al}-\mathrm{Si}$ killed steel but also in other types of steel, internal cracks have occurred along the interdendritic region.

In the equiaxed dendrite zone, one grain consists of one dendrite so that the inter-dendritic region corresponds to the grain boundary. On the other hand, in the case of the columnar dendrite zone, it is necessary to evaluate whether the region between two primary dendrite arms is the sub-grain boundary or the grain boundary. One criterion for the evaluation is the difference in the direction between the adjacent primary dendrite arms of the columnar dendrite.

There is also the superimposed structure as another evaluation criterion applicable to $\mathrm{Al}-\mathrm{Si}$ killed steel. The mechanism, by which this structure can be

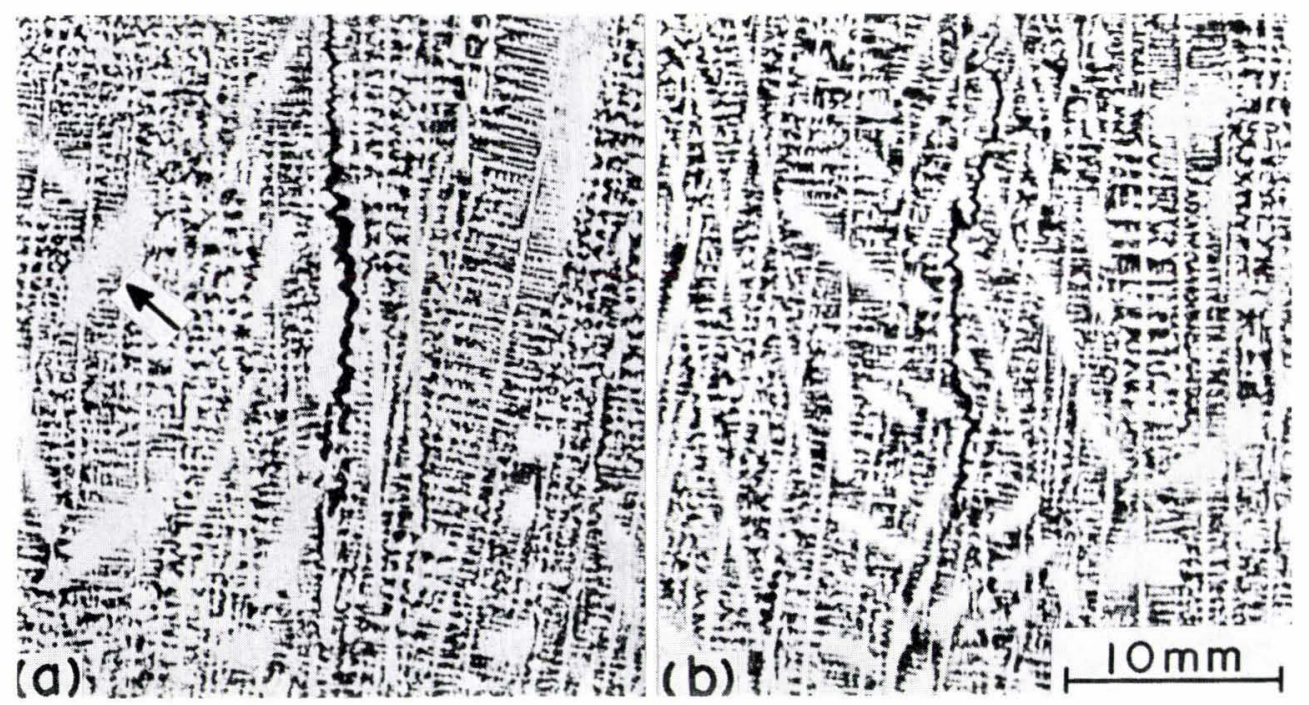

(a) An example showing that the internal crack does not intersect one superimposed structure

(b) An example showing that the direction of superimposed structure in each side of internal crack is different.

An arrow in the photograph indicates one of superimposed structures

Photo. 2. Cellular dendrite structure in Al-Si killed steel slab for plate with an internal crack 
formed, is analyzed by Suzuki et al., ${ }^{9)}$ and by means of this mechanism, the superimposed structure having the same direction can be observed in the same grain. Therefore, it follows that if internal cracks are to occur in the grain boundary, the superimposed structure will not be cut off by internal cracks, and that no internal cracks should be generated in between mutually adjacent columnar dendrites having the same directional superimposed structure. As a result of observation with the above method, it is found that as far as our research goes, there are no internal cracks generating across the superimposed structure, and that as Photo. 2 indicates, the direction of the superimposed structure on one side of the internal crack differs from that of the other side. Hence, it is concluded that internal cracks occur along the grain boundary both in the equiaxed and columnar dendrite zones.

\section{Structure of the Internal Crack}

\section{Results of Micro-analysis}

The metallographic structure of the area in the

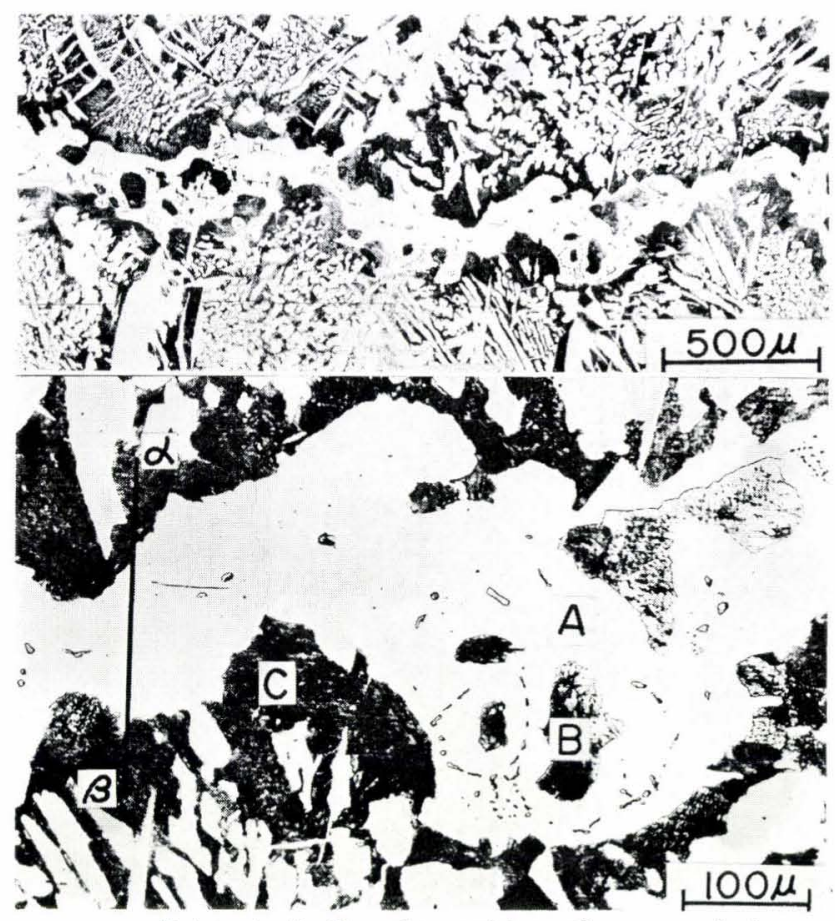

Points A, B, C: the position of spot analysis the path $\alpha-\beta$ : line scanning by electron microprove

Photo. 3. Photomicrograph of a filled crack etched in nital vicinity of the internal crack in Al-Si killed steel slabs for plate is shown in Photo. 3. Most of the internal cracks are filled and free from air space. It is the structure, which contains ferrite in its center surrounded by pearlite. In the center of the ferrite lies (Mn, Fe) S containing about $97 \% \mathrm{MnS}$.

Spot analysis and line analysis by EPMA were conducted at each position shown in Photo. 3.

Furthermore, a spot analysis of the ferrite and pearlite phases of the matrix was also conducted, and the beam radius was $3 \mu$. Results of the spot analysis are listed in Table 2, and results of the line analysis are available in Fig. 4.

From these results it is noted that in the internal crack, the three elements of $\mathrm{Si}, \mathrm{S}$ and $\mathrm{P}$ show clearly high values as compared with the matrix; this trend is particularly true for $\mathrm{P}$. In regard to $\mathrm{Mn}$, its content is small in the ferrite in the internal crack. If we consider the fact that $\mathrm{MnS}$ is aggregated in the center of the ferrite, however, there must be a high aggregation of $\mathrm{Mn}$ in the internal crack. As for $\mathrm{C}$, judging from its large diffusion coefficient in the solid phase and existence of the secondary aggregation concomitant with phase transformation, we find it

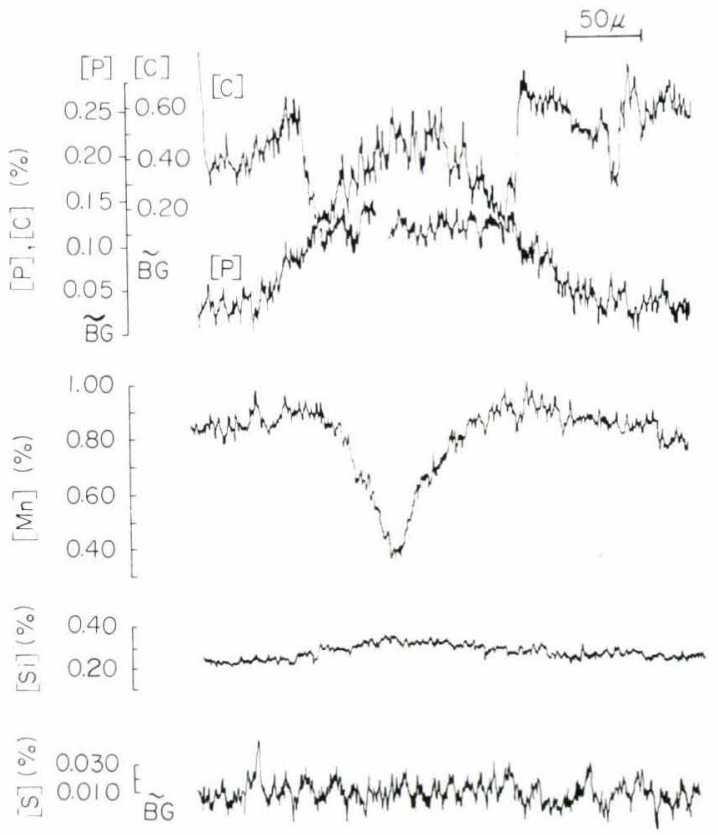

Fig. 4. Solutes distribution in the thickness direction of the internal crack indicated by the path $\alpha-\beta$ in Photo. 3

Table 2. Results of quantitative analysis by the E.P.M.A. of internal crack indicated in Photo. 3

\begin{tabular}{|c|c|c|c|c|c|c|}
\hline \multirow{2}{*}{\multicolumn{2}{|c|}{ Position of spot analysis }} & \multicolumn{5}{|c|}{ Composition (\%) } \\
\hline & & \multirow{2}{*}{$\frac{\mathrm{C}}{0.04}$} & \multirow{2}{*}{$\frac{\mathrm{Si}}{0.33}$} & \multirow{2}{*}{$\frac{M n}{0.61}$} & \multirow{2}{*}{$\frac{\mathrm{P}}{0.213}$} & \multirow{2}{*}{$\frac{\mathrm{S}}{0.016}$} \\
\hline & Ferrite A & & & & & \\
\hline Internal crack & Pearlite B & 0.52 & 0.30 & 0.92 & 0.048 & 0.016 \\
\hline & Pearlite C & 0.54 & 0.23 & 0.86 & 0.026 & 0.012 \\
\hline \multirow{2}{*}{ Matrix } & Ferrite & 0.05 & 0.20 & 0.69 & 0.005 & 0.009 \\
\hline & Pearlite & 0.51 & 0.20 & 0.70 & 0.008 & 0.008 \\
\hline \multicolumn{2}{|c|}{ Ladle analysis } & 0.18 & 0.18 & 0.74 & 0.016 & 0.020 \\
\hline
\end{tabular}


difficult to compare the value in the internal crack with that in the matrix.

As the foregoing discussion points out, each solute element shows a high concentration in the internal crack. As explained later, it goes to prove the validity of a notion that these solute segregations are formed as the solute enriched liquid present on the solidliquid interface is filled in the crack generated on the interface

\section{Ferrite Formation in the Internal Crack}

From the line analysis results shown in Fig. 4, the mechanism of ferrite formation in the internal crack can be estimated. $\mathrm{P}$ and $\mathrm{Si}$, which do not form any compound like $\mathrm{Mn}$ and $\mathrm{S}$ or develop any secondary segregation like $\mathrm{C}$, show a convex pattern of concentration distribution having its peak value at the center of the internal crack. This seems to indicate that the solute enriched liquid absorbed in the crack solidified toward the center of the internal crack.

$A c_{3}$ transformation temperature can be evaluated by the following equation: $\left.{ }^{10}\right)$

$$
\begin{aligned}
A c_{3}= & 908-223.7[\% \mathrm{C}]+438.5[\% \mathrm{P}]+30.49[\% \mathrm{Si}] \\
& +37.92[\% \mathrm{~V}]-34.45[\% \mathrm{Mn}]-23[\% \mathrm{Ni}] \\
& +2(100[\% \mathrm{C}]-54+6[\% \mathrm{Ni}]) \quad\left({ }^{\circ} \mathrm{C}\right) \ldots \ldots \ldots \ldots(
\end{aligned}
$$

Because of the large diffusion coefficient, $\mathrm{C}$ in the solute enriched liquid absorbed in the crack of the solid-liquid interface will reach a mostly uniform distribution of its concentration in several tens of seconds after the solute enriched liquid is fully solidified. Consequently, in the case of the crack in the present sample, Eq. (1) will become as follows. For C, $0.18 \%$, which is the value of the ladle analysis, is used.

$$
\begin{aligned}
A c_{3}= & 868+438.5[\% \mathrm{P}]+30.49[\% \mathrm{Si}] \\
& -34.43[\% \mathrm{Mn}] \quad\left({ }^{\circ} \mathrm{C}\right) \ldots \ldots \ldots \ldots
\end{aligned}
$$

Immediately before the $A c_{3}$ transformation, $\mathrm{MnS}$ is already precipitated. Diffusion has occurred to some, extent after the transformation. Nevertheless, Mn, $\mathrm{P}$ and $\mathrm{Si}$ values in the line analysis results in Fig. 4 can be considered as close to those immediately before the $A c_{3}$ transformation. Hence, if we substitute the line analysis results in Fig. 4 into Eq. (2), distribution of the $\mathrm{Ac}_{3}$ transformation temperature will have a profile similar to that of the $\mathrm{P}$ concentration distribution, and it will have the maximum of approximately $880^{\circ} \mathrm{C}$ at the center of the internal crack. At this position, ferrite is first precipitated from austenite. With the precipitation of ferrite, diffusion of $\mathrm{C}$ to the circumference occurs. Consequently, pearlite forms around the ferrite. The ferrite width is determined by the diffusion distance of $\mathrm{G}$ to the vicinity, namely, by cooling time to the $A c_{1}$ transformation temperature.

As explained above, if we consider that solidification occurs in one direction from both ends in contact with the matrix, then a phenomenon in which $\mathrm{MnS}$ is formed at the center of the internal crack can be explained.

\section{Scanning Electron Microscopic Examination of the Internal Crack Face}

Examination of the face of the internal crack, where air space could be visually noticed, was conducted by SEM, and a smoothly undulating face as shown in Photo. 4 was obtained. Such interface is also observed in the center porosity existing in the center segregation of the slab. ${ }^{11}$ From its form, the face is considered to be a free surface. Independent of the dendritic structure, the forms of the interfaces are about the same. They are likely to be tips of dendritic structure that is formed through the solidification of the liquid filled in the internal crack. Moreover, according to the examination by EPMA, on the interface can be observed Type II MnS, which is considerably larger than the one normally observed in a slab. This fact suggests that high concentration of $\mathrm{S}$ was contained in the liquid filled in the internal crack.

\section{Generation and Growth of the Internal Crack \\ 1. Method of Experiment}

For the purpose of confirming how the solute en-

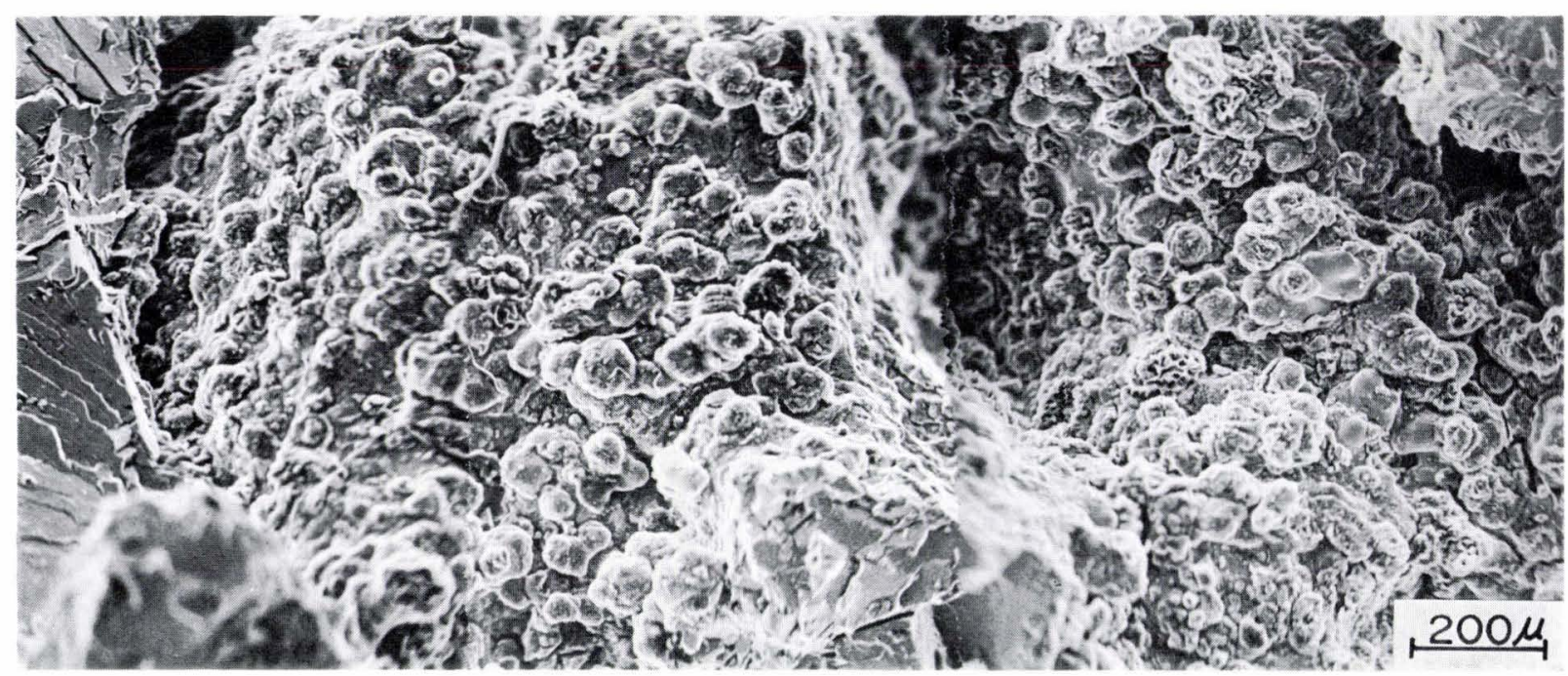

Photo. 4. Fractgraph of internal cracks by scanning electron microscope 
riched liquid on the solid-liquid interface was filled in the internal crack, a test was conducted to charge RI into a mold during the stable period of casting. RI used for the test was $\mathrm{Au}^{198}$, and the offered slab was Al-Si killed steel for cold rolled sheets presented in Table 1.

After casting, an autoradiograph of the longitudinal section and a sulfur print of the same section were made for examination of the internal crack.

\section{Position of Generation and Growth of the Internal Crack}

The autoradiograph, which permits observation of the internal crack, is shown in Photo. 5. The black portion on the outside is a part, which does not contain RI, and it is the part already solidified at the time of charging RI. The white or grey section inside is where a liquid containing $\mathrm{Au}^{198}$ was present, and this part corresponds to the liquid zone. The internal cracks are the winding lines, which appear the whitest, and this can be observed in the liquid zone containing RI. Its tip cuts into the solid section like a wedge: this phenomenon indicates that the internal crack occurs in the vicinity of the liquid-solid interface. A liquid containing RI flows into a slab section having a certain shell thickness. When the liquid solidifies, the RI enriched liquid is formed at the liquid-solid interface. In this condition, when a crack is formed near the solid-liquid interface by an external force, the RI enriched liquid penetrates into this crack. As a result, in the shell containing no RI can be observed a tip of the white, wedge-like internal crack, which has a high RI content.

In this manner, an internal crack is generated in the solid phase near the solid-liquid interface, and the solute enriched liquid lying at solidification front is absorbed in that section.

Furthermore, the internal crack, which is long in the slab thickness direction, is not formed at one time but produced through successive stages of development; this becomes clear as we compare the internal crack in the autoradiograph with that in the sulfur print in Photo 6. While the internal cracks as shown by two pictures in Photo. 6 should be identical, the internal crack observable in the autoradiograph shows only the section near its center, which was formed after RI charged. This means that one internal crack was formed at least more than twice of growth. Also, this phenomenon is noticeable over the entire length of the casting direction of the slab. Therefore, it is concluded that the internal crack is a product of successive stages of growth.

\section{Causes of Occurrence of the Internal Crack}

Figure 5 presents the results of measuring thickness of the solidification for the above explained RI charged test and the distance of the internal crack from the slab surface as observed in the autoradiograph. This leads us to believe that under these casting conditions, unbending of slab was performed after complete solidification. Consequently, the external force, which causes the internal crack to occur, can be due to bulging correction. The maximum amount, $\delta$, of bulging between rolls can be obtained by the following formula from the creep model of the plate explained in Appendix.

$$
\begin{aligned}
\delta= & \beta \cdot \sqrt{t / S^{3}} \ldots \ldots \ldots \ldots \ldots \ldots \ldots \ldots \ldots \ldots \ldots \ldots \\
\beta= & 12\left(1-\nu^{2}\right) \cdot q \cdot \alpha \cdot a_{0} \cdot \mathrm{a}^{4} \ldots \ldots \ldots \ldots \\
\alpha= & \frac{2}{\pi^{5} \cosh \left(\frac{\pi \mathrm{b}}{2 \mathrm{a}}\right)}\left\{2 \cosh \left(\frac{\pi \mathrm{b}}{2 \mathrm{a}}\right)\right. \\
& \left.-\left(\frac{\pi \mathrm{b}}{2 \mathrm{a}}\right) \tanh \left(\frac{\pi \mathrm{b}}{2 \mathrm{a}}\right)-2\right\} \ldots
\end{aligned}
$$

where, $S$ : shell thickness $(\mathrm{mm})$

$t$ : creep time (min)

ข: the Poisson ratio

$q$ : ferrostatic pressure $\left(\mathrm{kg} / \mathrm{mm}^{2}\right)$

$a_{0}$ : creep constant $\left(\mathrm{mm}^{2} / \mathrm{kg} \cdot \mathrm{min}^{1 / 2}\right)$

a: roll pitch $(\mathrm{mm})$

b: slab width $(\mathrm{mm})$.

The internal strain, $f$, caused by bulging correction on the solid-liquid interface is given by the following equation, and is shown in Fig. 6.
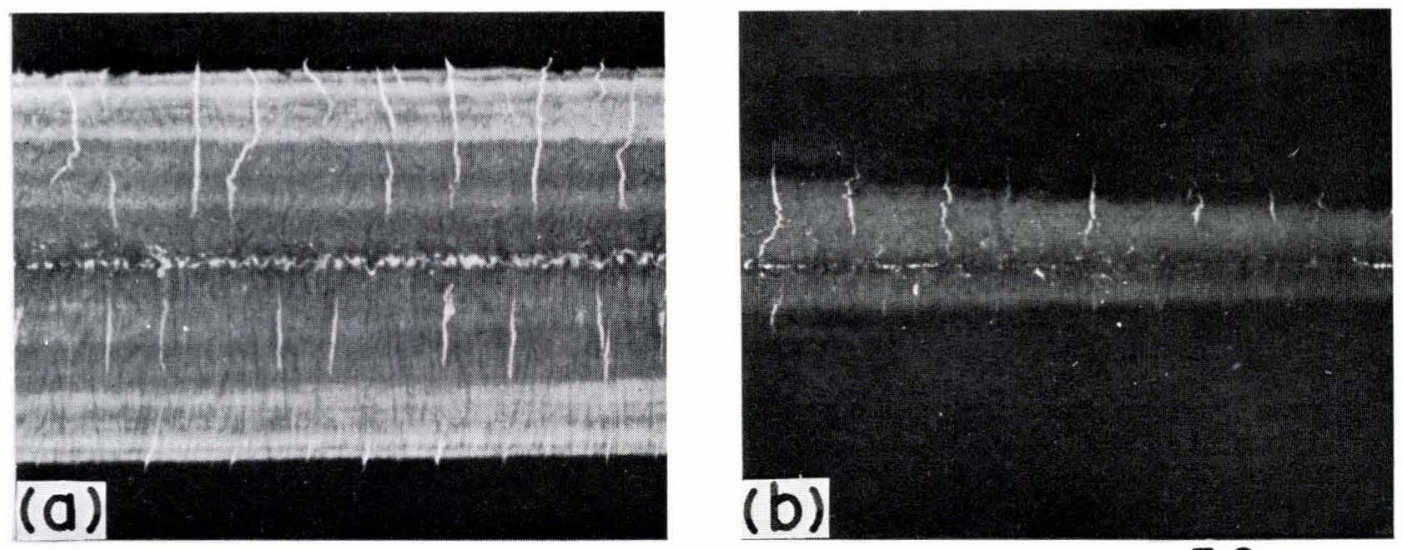

(a) about $3.5 \mathrm{~m}$ from meniscus

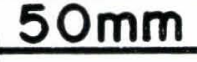

(b) about $6.5 \mathrm{~m}$ from meniscus

Photo. 5. Autoradiographs of solidified shell with internal cracks 


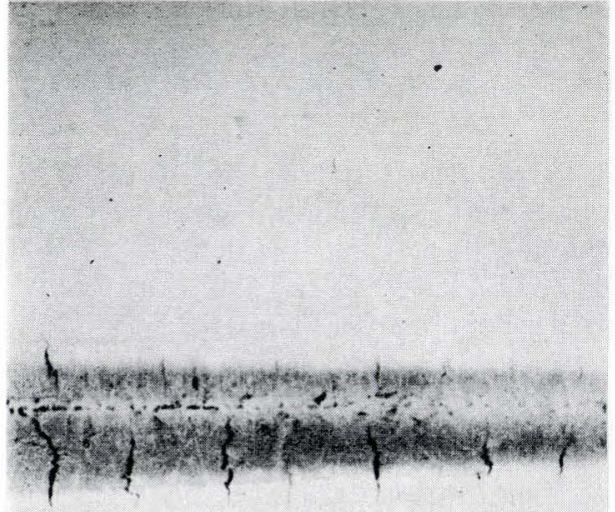

(a)

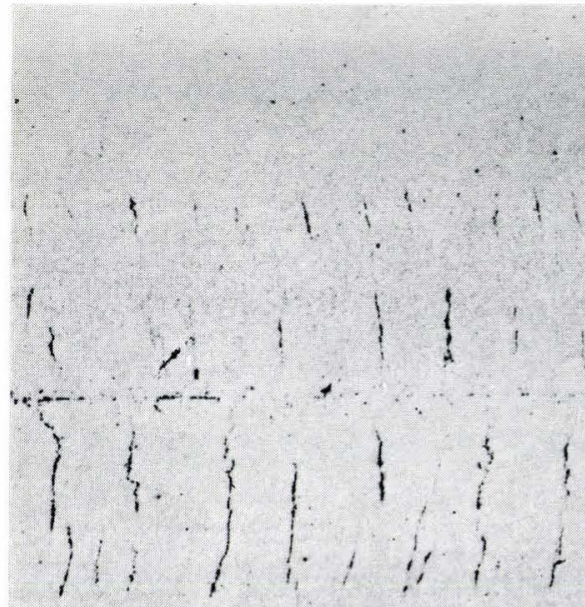

.

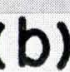

(b)

$50 \mathrm{~mm}$
Photo. 6

(a) Autoradiograph and (b) sulfur print of the same longitudinal cross section of slab. Photograph 6 (a) is printed reversely to Photo. 5 (b) for the sake of comparing the internal cracks with those in the sulfur print.

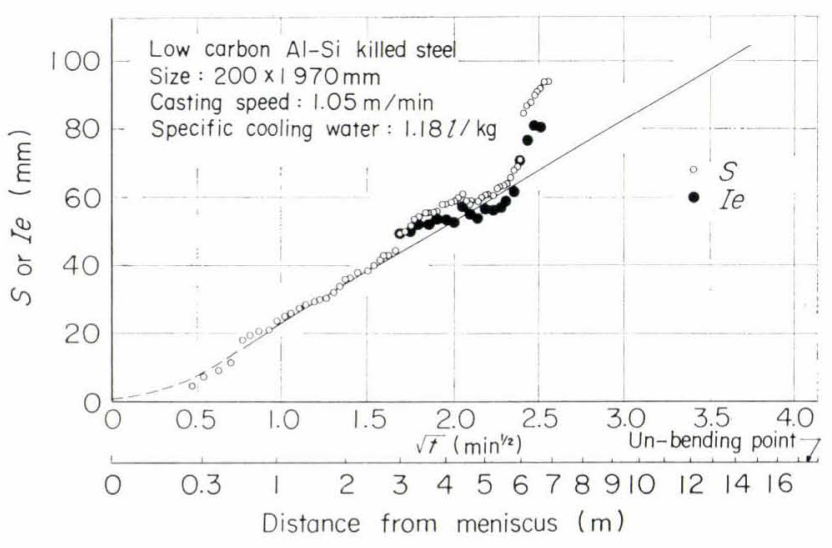

Fig. 5. Relation between casting time and shell thickness, $S$, or the distance, $I e$, between slab surface and internal cracks observed in autoradiographs

$$
f=1600 \cdot \delta \cdot S / \mathrm{a}^{2}
$$

From Fig. 6, it is noted that at the joint of each segment, $f$ tends to become high, and that on the average, it tends to increase as distance is gained from the meniscus. This is understandable from the fact that the roll pitch increases step by step.

The originating point of the internal crack is about $50 \mathrm{~mm}$ from the slab surface. If we take into consideration the solidification thickness measured in Fig. 5 and the strain by bulging correction at each roll in Fig. 6, it is estimated that generation of the internal crack of the sample slab cast in this machine is due to correction of No. 16 roll.

When we consider the fact that a distance of the internal crack tip from the slab surface as observed in the autoradiograph of Fig. 5, increases gradually as the distance from the meniscus increases, the internal crack does not grow at the joint of the segment alone. After occurrence at the No. 16 roll, the

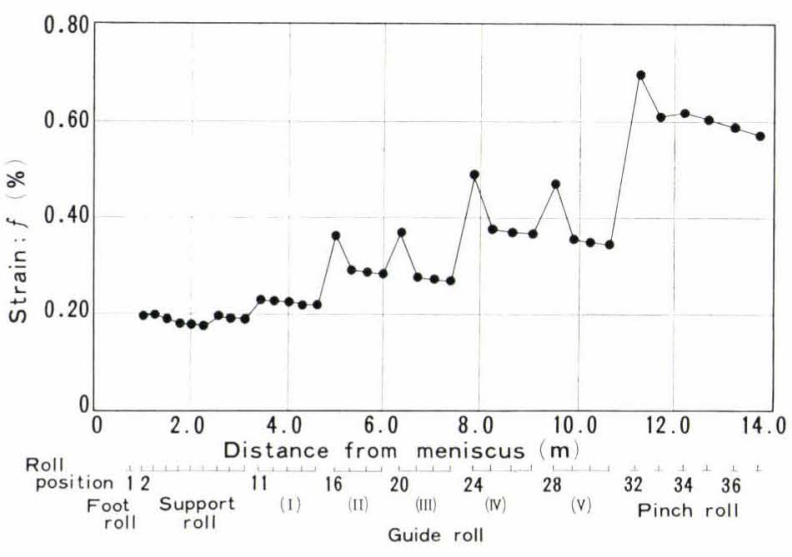

Fig. 6. Calculated values, $f$, of strain at solid-liquid interface by correcting of the bulging between neighboring two rolls

internal crack grows step by step through correction at each roll. In this case, the crack length, $L_{0}$, at one time is the sum of the length $L$ of the internal crack tip biting like a wedge into the solid phase, which can be observed in the autoradiograph, and an increment, $\Delta S^{\prime}$, of thickness of the shell solidifying within the time from when the liquid containing RI flows into the liquid zone to when the crack is formed.

$$
L_{0}=L+\Delta S^{\prime}
$$

Figure 7 presents the relationships among length $L$ of the internal crack tip, increment $\Delta S$ of thickness of the shell during passage of one roll pitch (maximum of the above mentioned $\Delta S^{\prime}$ ), and $\sqrt{t}$, where $t$ is the casting time. In the results of shell thickness measurement given in Fig. 5, the values suddenly increase when the $\sqrt{t}$ value is around 2.5 , because liquid flow rate decreases near the end of the crater. Assuming that the shell thickness follows the solid line 


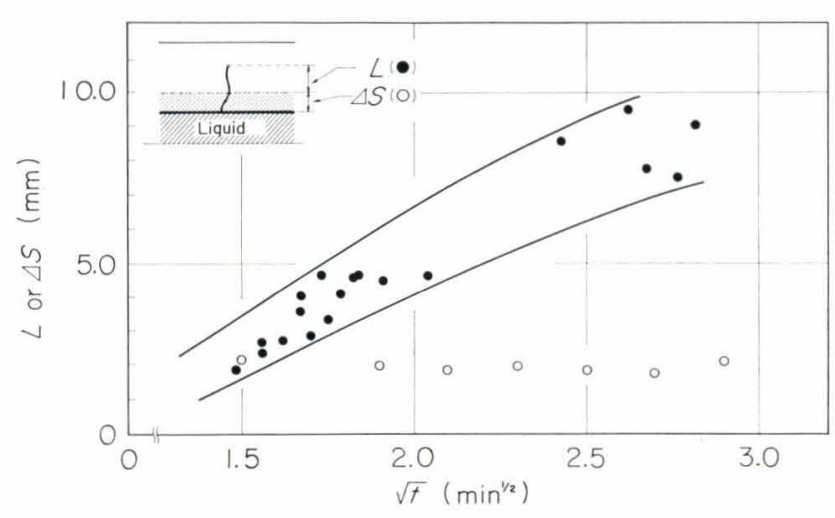

Fig. 7. Relation between casting time and the penetrated length of internal crack $(L)$ or the shell thickness increased during one roll pitch $(\Delta S)$

in Fig. 5, we obtain the relationsips among $L, \triangle S$ and $\sqrt{t}$ as shown in Fig. 7 .

According to the relationships, $\Delta S$ is approximately $2 \mathrm{~mm}$ over the entire range $(\sqrt{t} \geq 2.0)$ of measurement, while length $L$ of the internal crack tip becomes longer with an increase in $\sqrt{ } t$ as can also be observed by comparing the two pictures in Photo. 5. At the initial stage of internal crack formation, $L$ is about $5 \mathrm{~mm}$ and about $10 \mathrm{~mm}$ at the final stage. Bulging correction strain as shown in Fig. 6, which increases as the distance from the meniscus grwos, and a reduction in the temperature gradient in the vicinity of the solid-liquid interface, can be considered as possible cause of this. Although bulging correction strain in the range of 4 to $7 \mathrm{~m}$ from the meniscus is roughly constant, length $L$ of the internal crack tip increases as shown in Fig. 7. This leads us to believe that the latter effect is greater. When a crack is generated near the interface to extend to inside the solid phase, material strength, which can prevent it, depends upon its temperature.

Therefore, if we consider that the crack will extend from the solid-liquid interface to the solid phase possessing the critical temperature $\mathcal{T}_{\mathrm{c}}$, length $L_{0}$ of the crack at one time will depend on the temperature gradient in the solid phase side near the solid-liquid interface. This temperature gradient will become less as solidification advances so that Length $L_{0}$ of the crack at one time is estimated to become longer.

As the above discussion shows, under the current casting conditions, bulging correction stress is cited as the major cause of the internal crack. But, depending upon the type of continuous casting machine and casting conditions, it may be necessary to take account of reciprocal action such as correction stress and thermal stress.

\section{Relationships with the Ductility of Steel at High Tem- perature}

Metals and alloys have a region of extremely low ductility during or immediately after solidification. When a stress due to solidification shrinkage or other external stress is applied to a metal or an alloy in this region, a crack is generated as it becomes unable to withstand such force. This region of low ductility is called the brittleness temperature range. Inasmuch as the internal crack occurs near the solidliquid interface, it is considered to be a phenomenon occurring in this range. Hence, high temperature characteristics of slab near the solidus line are called into question.

In high temperature tensile test of continuously cast slabs, as the $\mathrm{C}$ and $\mathrm{S}$ contents decrease, the transition temperature from ductile- to brittle-fracture becomes higher. ${ }^{12)}$ As a result, the brittleness temperature range is narrowed, and it becomes qualitatively difficult for cracks to occur. ${ }^{13)}$ As shown in Fig. 3, this is in keeping with the outcome of the effects of $\mathrm{C}$ and $\mathrm{S}$ upon frequency, with which internal cracks occur.

However, there are still many unclear points about the brittleness mechanism in this temperature range, whose resolution calls for further study.

\section{Conclusions}

While the effects of the casting conditions upon the internal crack of continuously cast slabs are sorted out, a metallographic investigation of the internal crack and an isotope analysis of the conditions for its generation were conducted to obtain the following conclusions.

(1) Factors greatly contributing to the internal crack generation are the casting speed and specific cooling water, which jointly determine the marginal casting conditions for the internal crack generation. They also have effects on the internal crack form. The larger the casting speed, the longer the internal crack length and the shorter its pitch.

(2) Effects of solute elements are observed, too. With increases in the $\mathrm{C}$ and $\mathrm{S}$ contents, it becomes easier for the internal crack to occur.

(3) The internal crack has occurred along the grain boundary, and differences due to slab's dendritic structure are noticeable. In other words, it is more difficult for the internal crack to occur in the equiaxed dendritic zone than in the columnar dendritic zone.

(4) The internal crack is a structure centered by ferrite, which is surrounded by pearlite in a belt form. In the ferrite is an aggregation of sulfides containing approximately $97 \% \mathrm{MnS}$.

(5) Inner surface of the internal crack is smooth and granular. It is estimated that this is a free surface at the time of solidification.

(6) It is observed that the internal crack is generated on the solid-liquid interface, growing step by step due to bulging correction.

\section{REFERENCES}

1) K. Ushijima: Tetsu-to-Hagané, 47 (1961), 116.

2) H. Krainer and B. Tarmann: JISI, 196 (1958), 105.

3) L. Backer and P. Gosselin: Open Hearth Proceedings, 53 (1970), 145.

4) J. W. Donaldson: J. Metals, 17 (1965), 1338.

5) G. Van Drunen, J. K. Brimacombe and F. Weinberg: Ironmaking and Steelmaking, 2 (1975), 125. 
6) C. J. Adams: Open Hearth Proceedings, 54 (1971), 290.

7) W. J. Lankford, Jr.: Met. Trans., 3 (1972), 1331.

8) K. Kumai, K. Asano, T. Ohashi, E. Nomura and H. Fujii: Tetsu-to-Hagané, 60 (1974), 156.

9) A. Suzuki and T. Suzuki: J. Japan Inst. Metals, 32 (1968), 571.

10) S. Owaku: Kinzoku Netsushori Gijutsu Binran, Nikkan Kogyo, Tokyo, (1961), 137.

11) S. Takaishi, T. Komai and K. Shimazu: Tetsu-to-Hagané, 62 (1976), S87.

12) H. Fujii, M. Oda, T. Ohashi and T. Hiromoto: Tetsu-toHagané, 62 (1976), S93.

13) T. Senda, F. Matsuda, K. Watanabe, M. Takano and T. Matsuzaka: Trans. The Japan Welding Society, 2 (1971), 1.

14) M. Naruoka, Y. Niwa, Y. Yamada and S. Shiraishi: KozoRikigaku, III, Maruzen, Tokyo, (1970), 111.

\section{Appendix}

\section{Calculation of the Bulging Equation}

Assume that a rectangular plate, four sides supported, is subjected to a uniform load $q$. Plate material is isotropic and homogeneous, its thickness $h$ is far less than its width $b$ and length a. Also, assume that points on a perpendicular line to the central face remain on the perpendicular line to the central face, which is bent after deformed. Further, if the bend of the plate is considered to be less than plate thickness, any expansion, contraction and slip taking place on the central face can be ignored. Hence, we can assume that elements on the central plate will not strain.

Consider the plate in relation to the axis of coordinates $(x, y, z)$. Take the $\mathrm{x}$ and $\mathrm{y}$ axes on the plate with the $z$ axis perpendicular to the plate. It is assumed further that the points $(x, y, 0)$ on the central face will change their position by $\omega$ in the $z$ direction. Each strain component, $\varepsilon_{x}, \varepsilon_{y}$ and $\varepsilon_{x y}$, is

$$
\begin{aligned}
\varepsilon_{x} & =-Z \frac{\partial^{2} \omega}{\partial x^{2}}, \quad \varepsilon_{y}=-Z \frac{\partial^{2} \omega}{\partial y^{2}}, \\
\varepsilon_{x y} & =-2 Z \frac{\partial^{2} \omega}{\partial x \partial y} \ldots \ldots \ldots \ldots \ldots \ldots \ldots \ldots \ldots \ldots \ldots
\end{aligned}
$$

The creep is empirically represented from some measurements by the following equations.

$$
\varepsilon_{x}=a_{0}\left(\sigma_{x}-\nu \sigma_{y}\right) t^{n}, \quad \varepsilon_{y}=a_{0}\left(\sigma_{y}-\nu \sigma_{x}\right) t^{u}
$$

The bending moment is

$$
M_{x}=\int_{-h / 2}^{h / 2} \sigma_{x} \cdot Z \cdot d z
$$

$$
M_{y}=\int_{-h / 2}^{h / 2} \sigma_{y} \cdot Z \cdot d z
$$

From Eqs. (A-1) to (A-3), one obtains

$$
\begin{aligned}
& M_{x}=\frac{-h^{3}}{12 a_{0}\left(1-\nu^{2}\right) t^{n}}\left(\frac{\partial^{2} \omega}{\partial x^{2}}+\nu \frac{\partial^{2} \omega}{\partial y^{2}}\right) \\
& M_{y}=\frac{-h^{3}}{12 a_{0}\left(1-\nu^{2}\right) t^{n}}\left(\frac{\partial^{2} \omega}{\partial x^{2}}+\nu \frac{\partial^{2} \omega}{\partial y^{2}}\right)
\end{aligned}
$$

Eliminate $\partial^{2} \omega / \partial x^{2}$ from Eq. (A-4), and replace with the moment of the plate. ${ }^{14)}$ Then, one gets

$$
\begin{aligned}
\frac{\partial^{2}(\omega)}{\partial y^{2}}= & \frac{-12 a_{0} t^{n}}{h^{3}} \cdot \frac{4 q \mathrm{a}^{2}}{\pi^{2}} \cdot \frac{1}{2 \cosh \left(\frac{\pi \mathrm{b}}{2 \mathrm{a}}\right)} \\
& \times\left\{\left(\frac{\pi \mathrm{b}}{2 \mathrm{a}}\right) \tanh \left(\begin{array}{c}
\pi \mathrm{b} \\
2 \mathrm{a}
\end{array}\right) \cdot \cosh \left(\frac{\pi y}{\mathrm{a}}\right)\right. \\
& \left.-\left(\frac{\pi y}{\mathrm{a}}\right) \sinh \left(\frac{\pi y}{\mathrm{a}}\right)\right\} \sin \left(\frac{\pi x}{\mathrm{a}}\right) \ldots \ldots
\end{aligned}
$$

The following conditions are used to solve Eq. (A-5).

$$
\begin{aligned}
\partial \omega / \partial y= & 0(\text { at } y=0), \quad \omega=0(\text { at } y= \pm \mathrm{b} / 2) \\
\omega= & \frac{12 a_{0} g \mathrm{a}^{4}\left(1-\nu^{2}\right)}{h^{3}} \cdot t^{n} \frac{1}{\cosh \left(\frac{\pi \mathrm{b}}{2 \mathrm{a}}\right)} \cdot \frac{1}{\pi^{5}} \\
& \times\left\{2 \cosh \left(\frac{\pi \mathrm{b}}{2 \mathrm{a}}\right)-\left(\frac{\pi \mathrm{b}}{2 \mathrm{a}}\right) \tanh \left(\frac{\pi \mathrm{b}}{2 \mathrm{a}}\right) \cosh \left(\frac{\pi y}{\mathrm{a}}\right)\right. \\
& \left.+2 y \sinh \left(\frac{\pi y}{\mathrm{a}}\right)-2 \cosh \left(\frac{\pi y}{\mathrm{a}}\right)\right\} \sin \left(\frac{\pi}{\mathrm{a}}\right) x \ldots \ldots(
\end{aligned}
$$

In Eq. (A-6), the $x$ axis $(y=0)$ bend is obtained by

$$
\omega_{x}=\beta \frac{t^{n}}{h^{3}} \sin \left(\frac{\pi}{\mathrm{a}}\right) x
$$

where,

$$
\begin{gathered}
\beta=12\left(1-\nu^{2}\right) \cdot \alpha \cdot q \cdot \mathrm{a}^{4} \cdot a_{0} \\
\alpha=\frac{2}{\pi^{5} \cosh \left(\frac{\pi \mathrm{b}}{2 \mathrm{a}}\right)}\left\{2 \cosh \left(\begin{array}{l}
\pi \mathrm{b} \\
2 \mathrm{a}
\end{array}\right)\right. \\
\left.-\left(\frac{\pi \mathrm{b}}{2 \mathrm{a}}\right) \tanh \left(\frac{\pi \mathrm{b}}{2 \mathrm{a}}\right)-2\right\}
\end{gathered}
$$

In the case of mild steel, $n=0.3 \sim 0.6$, hence 0.5 is chosen.

The amount of bulging $\delta$ is the maximum value of $\omega_{x}$, and it can be obtained by the following equation:

$$
\left(\omega_{x}\right)_{\max }=\beta \frac{\sqrt{t}}{h^{3}}
$$

